\title{
The Aesthetics of some Kasem Traditional Prayers
}

\section{Umar Abdul-Hakim}

Gur-Gonja Department, University of Education, Winneba, P. O. Box 25, Winneba, Ghana, West Africa Email : abdulhakimnav@gmail.com

\begin{abstract}
:
This study examines the aesthetics of three Kasena traditional prayers performed in devotion to Kukula, a divinity revered by the Kasena of the Upper East Region of Ghana. These prayers are performed orally and have not received any literary study in Kasem; this study is therefore aimed at filling this gap by looking at the aesthetics in this prayers. Four different prayers were recorded and transcribed by the researcher; these prayers were collected from Kayoro, a village in the Kasena Nankana West District in the Upper East Region of Ghana. We define these prayer texts as being part of Kasem oral literature. The literary theory of structuralism is adopted for this study. The instruments I used in collecting the information for this study included, voice recorder, video recorder, while the researcher used active participatory method of observation and data elicitation in the data collection. The analysis reveals that the officiant in their performances of these prayers use native poetic devices such as; proverbs, rhetorical questions, metaphor, personification, oxymoron, synecdoche, symbolism, imagery and repetitions of varying degrees. They also use allusions, alliteration and assonance. The study of these prayers reveals that these performers have a mastery of many artistic devices native to Kasem. In conclusion the study clearly shows that even though the officiants of these traditional prayers are merely performing religious activities, they use literary language during their compositions, thus, making Kasena traditional prayer texts artistic compositions.
\end{abstract}

Keywords :

Aesthetics; Kasem Traditional Prayer; literature; God.

\section{Introduction}

The discussions of the aesthetics of oral literature in Africa, especially, West Africa are sparse and general. For example, Finnegan (2005) in her reference to the oral narrative tradition in some West African communities. The term aesthetics was introduced in 1753 by the German philosopher, Alexander Gottieb Baungarten. It was derived from the ancient Greek word aisthanomai meaning perception by senses. Aesthetics as a branch of philosophy deals with the nature of art, beauty and taste, with the creation and appreciation of beauty. More broadly, aesthetics is seen as critical reflection on art, nature and culture. As a field of study, aesthetics involves ways of seeing and perceiving the world, as well as new and novel interpretations. In the early work of Plato he postulated that all things of sensory beauty were imitations of the perfect form of their objectivity, different aesthetic values are found in varied cultures around the world that have been nurtured by diverse natural environments, cultural norms and moral foundations. In India, for instance, aesthetic values have evolved through interpretation and representation of spiritual and religious iconography. Art relationship between the physical and spiritual states is manifested in paintings, sculpture, literature, dance, architecture and music (http://paulford.com/what-is-aesthetics retrieved on 29/07/ 2013).

In a more detailed discourse of the aesthetics of Krio narratives, Broderick (1977) identifies some specific aesthetic phenomena and devices in Krio narrative tradition. Azasu (2007) worked on Abidjan Mamiwater: A Creative Preserver and Contribution to Ewe Visual, Verbal and Musical Arts, has proved the existence of aesthetic features in African traditional religious prayers, chants and songs. 
Agu (1991) worked on Songs and War: The Mixed Message of Biafran War Songs has also shown some aesthetic features in the songs he studied.

Literature in general has content and form; the two are complementary and not independent of each other since the absence of one will render the work not a literary one. The most vital point of these two constituents is the beauty of form as well as the provision of an emotional effect which can be appreciated by those who come into contact with it. In determining what constitutes a literary work one has to reflect on the collective values and postulation, world view and other fundamental elements of the culture of the people.

The transmission mode of oral literature makes it possible to classify it as a speech communication. Hastling (1993) declares that in delivering a message there should be dimensions such as the primary and auxiliary messages. Primary message, according to him, is the verbal content of the speech, that is, words used by the speaker to express his ideas, views and opinions that form the substance of the message. This is the meaning the audience would get if the channel of communication were to be printed rather than spoken. Auxiliary messages are the dimensions that can be added when the message is delivered orally. This includes what the speaker can do deliberately to enhance the reception of the primary message such as the tone of the voice, posture of the speaker, gestures, eye contact and the diction. Hastling's ideas are vital to this study because in the performance of Kasem traditional prayers the audience must, as well as the divinity, understand and appreciate the performance.

The spiritual world of Africans is full of spirit beings, this include the living and dead (Mbiti, 1970). Africans believe in a Supreme Being who is believed to be the creator of the universe and all therein; in addition, Africans believe in other spiritual forces that are believed to have powers, often times, for specific purposes. Among these spirit beings are the ancestors. Some scholars of African Traditional Religion classify the belief system of the Africans into four types: The supreme God, the sky god, the mother earth and other divinities (Parrinder, \& Parrinder, 1976). Mbiti (1975) also postulates that every African people recognized God according to some cosmologies. (www.ajol.info)

Scholars of African Traditional Religion tell us that all African societies believe in God. Some African religions believe in the one supreme God who created the world and all that is in the world, while others believe that there is more than one God. However, even in these religions, usually one of the "gods" is claimed to be the supreme God who was responsible for creating the world. (exporingafrica.matrix.msu.edu)

Language can be said to be a system of human communication in which words (spoken and written) are used by man to communicate his thoughts, feeling and ideas to other human beings, divinities and God depending on the supplicants' beliefs. When man is in distress, he may seek for assistance from divinities and, in some cases, God. We pray to our divinities for assistance in times of need as well as happiness. These prayers are performed using language which serves as a preserve of the oral traditions of man.

Prayer is an act of speech and other activities that seek to activate rapport between human beings and divinities through deliberate communication; it is a form of religious practice that may be performed by an individual or a community and takes place both privately and publicly. Only prayers invite God's presence and God's presencebrings benediction. It is through knowing God in prayer that $\mathrm{He}$ is able to touch man's condition and give divine revelations. Many of God's 
servants are unfit for the Lord's work because they do not have prayer life. A prayerful servant is not only of use to God, but also knows the direction God is leading him.

Ekwunife (2007) further defines prayer as a spiritual means through which a religious woman or man interiorly and externally communicates with God and all super-sensible beings of His invisible world. In prayer, the religious man expresses faith-conviction that in earthly world is meaningful without transcendence. Prayer is, therefore, man source of energy that sustains and directs his journey to eternity.

There are various definitions of prayer and, in many cases, it is rather described and in some other cases, the description is influenced by one's religious affiliation. In all, prayer portrays one's dependency on a more superior and supernatural being. In prayers too, one's incapability, powerlessness and helplessness are acknowledged.

There are different forms of prayer, namely petitioning prayer, prayer of supplication, thanksgiving prayer, devotional prayer just to mention but a few, among the Kasena. However, these prayers may be directed towards a divinity, a spirit, spirit of the dead and God depending on one's religious beliefs. Devotion is religious observance or prayer (usually spoken silently).Prayer of supplication is the act of communicating with a divinity (especially as a petition or in adoration or contrition or thanksgiving).Kasena have spontaneous prayers, which are said in times of crisis and they are of no artistic interest since they are mostly a name of a divinity mentioned by a person in times of crisis.

The Kasena, however, have a form of prayer which is of artistic value because it does not only involve the use of words, it also involves the pouring of millet water or alcohol, slaughtering of an animal or a fowl and the blood used as well as some parts of the animal being roasted and symbolically placed on an icon representing the divinity (structure built to represent it) or on the bare ground.

African Traditional Religious prayers are poetic genres which are aspects of oral literature because, as it is, they "rest on the basis of language" (Finnegan, 1992). However, this area of oral literature has not received enough attention by both literary and linguistic scholars of minority languages in Africa, while they abound with unique aesthetic features.

\section{Theoretical Framework}

The literary theory of structuralism is adopted for this study. Structuralism in literary studies is concerned with an analysis of texts based on some linguistic principles; it is an intellectual movement that made significant contributions not only to literary criticism but also to philosophy, anthropology, sociology and history. This theory draws on the work of the Russian formalists, as well as linguistic theories of Ferdinand de Saussure and C. S. Peire. Literary structuralism views literary text as systems of interlocking signs and seeks in a scientific way the rules and codes that govern the form and content of all literature. Levi Strauss (1972) postulates that human activity and its products, including religion, social environment, ritual, art and philosophy, are artificial constructions and not natural. They are all elements of a structure and derive their meaning not from the world of reality, but from their relationship to each other within a language system which sustains our perception of reality because the world like language, is made up of signs (www.nou.edu.ng). 
Structuralist analysis seeks to use scientific way to make explicit the logic that governs the form and content of all literature (written and oral) concentrating on signs (language) in a given text. Language is seen as a complete, self-contained system and deserves to be studied as such (www.nou.edu.ng).

\section{Discussion}

\subsection{The Religion of the Kasena}

The Kasena speakKasem, a Gur-Language of the Grusi sub-branch belonging to the OtiVolta branch of the Niger Congo group of languages.The Oti-Volta languages form a subgroup of the Gur-languages, comprising about 30 languages of northern Ghana, Benin, and Burkina Faso spoken by some twelve million people. These languages are largely mutually intelligible (Naden, 1998 in www.enotes.com).

The religion of the Kasena people traditionally is, like all other traditional religions, oriented towards ancestors "chira" and divinities "tangwana". The Kasena, as part of their religion, belief the recent dead receive food as, it is believed they still visit the home until such a time that the living perform all funeral rights to pave the way for their entry into the spirit world. The Kasena people also believe these ancestors are to ensure that the living enjoy prosperity and well-being since they are believed to be closer to the divinities which are in communion with the Earth and God. If the living violates any of the norms sanctioned by the ancestors they are punished with illnesses and misfortune or may be called over by the ancestors to answer queries through death. The divinities "tangwana", shrines "jwona", ancestors "chira" and diviners "vora" can intervene to better the lives of the living. The Kasena religion is basically practiced through divination, performance of various prayers, mostly prescribed by a diviner or diviners. These traditions are passed on from one age group to the other through the use of oral myths, folktales, legends and initiation (see Awedoba, 2000).

\subsection{Analysis}

Active participatory observation method and data elicitation were the main tools used in collecting the data from officiant of the prayers at KayərJ, north-west of Navrongo Township, a Kasem speaking community in the Upper East Region of Ghana.

Prayer means communication with God directly or through a divinity. Prayer leads us into dependence upon God and divinities depending on our religious beliefs. Kasem Traditional prayers are mostly in the form of free verses in lines. In most instances, these prayers are either short or long depending on the purpose and circumstances under which they are performed.

The language used is mostly determined by the officiant. This is done in anticipation that the divinity and the congregation would appreciate the language of the officiant leading to the acceptance of the prayer by the divinity and the congregation. The prayers were transcribed using the current autography of the Kasem language without any coloration and translated into English before analyzing them using the original Kasem version because this research is done on Kasem. The analysis is guided by the framework of non-referential approach to meaning.

\section{A. Analysis of Prayer Text 1 (P. T. 1 Ref. Appendix I)}

The prayer opens with an invocation of the Supreme Being by the officiant thus “ $\boldsymbol{A}$ kwo baja $\boldsymbol{W} \boldsymbol{\varepsilon}$ ” which means 'My Father Almighty God'. 
Theme: The prayer treats the following themes:

1. Reverence to the divinity as in;the uses of anaphora: "Ba nüi" meaning "they came through' is repeated at the beginning of the two lines below.

Ba nujizambaabayamo

Ba nuyiwalewogoba baa togeKatiupupwojo

They came throughzambaa

They came throughwalewogo and came and passed Katiupupwono

The officiant used this rhetorical repetition to remind Kukula of his strength and importance which makes the people ignore other divinities in other towns to travel to him.

In line 11, (Ref. Appendix I, P. T. 1), “Kukulajwoni” which means 'Kukula collect' is a personification in reverence to Kukula, it also apostrophises the divinity.

The theme of need unobtrusively is insinuated in the prayer in the following lines; line 11, (Ref. Appendix I, P. T. 1), is presented as to making the divinity have had human personality of being able to collect things physically. Personification is the attribution of human qualities or other characteristics to anything other than a human being. This is used to appeal to the divinity to allow his praises to be recorded and used for the study which show the above theme clearly.

Style: Use of Words

\section{Repetitions of Varying Degrees:}

\section{Assonance;}

AjagwoniKatiu ne mojaanenosnabanto o ba Ye ba baa ta o webalagenmobugaKukulaseina.

Ajagwoni from Katiu has come with this people

And they came and said they want river Kukula's praises.

The officiant applied the aesthetic device of assonance in the second line above. The /a/ in "ba" 'came', "ta" 'said', "ba" 'they', "buga" 'river' and "Kukula" 'name of a divinity' creates an internal rhyme in that line to make it rhythmic.

The /y/ and /a/ sounds in the line "ye ba laam yi ywo" meaning "before they came here' also exemplifies assonance which makes the line rhythmic.

\section{Anaphora;}

The recurrence of the word ' $\mathbf{N} \boldsymbol{i}$ " 'look' in the beginning of the lines below constitutes anaphora which the officiant uses artistically to create emphasis and implore the divinity not to ignore the sacrifice. This anaphora also creates a rhyming effect in the prayer. 


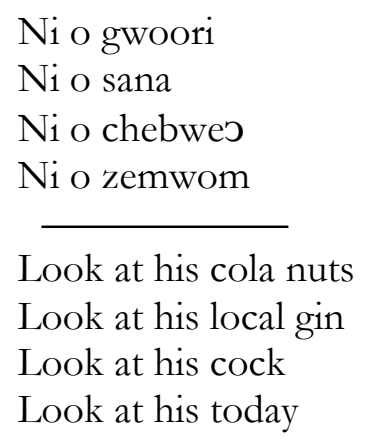

The officiant in trying to lay emphasis on the items being sacrificed and their individual sources for the sake of transparency to the divinity and the congregation used this type of repetition.

2. Historical Metaphor; "Ni o zem wom"which means 'look at his today' is a metaphorical reference to money. This is because the Kasena traditionally did not use currency notes hence his reference to them as 'today' meaning 'money'. This is an ingenious historical metaphor.

3. Personification; in line 11, (Ref. Appendix I, P. T. 1), "Kukula jwoni" which means 'Kukula collect' is a personification in reverence to Kukula, it also apostrophizes the divinity. This is presented as to making the divinity have had human personality of being able to collect things physically. Personification is the attribution of human qualities or other characteristics to anything other than a human being.

\section{Structure:}

The above prayer is a sixteen line prayer in one stanza. There is no conscious or an unconscious effort by the officiant to perform the prayer in discernible parts.

\section{Conclusion:}

The diction is simple as the tonation used in this prayer is not in a definite pattern; however, the anaphora and assonance identified above enhances the intonation. Kasem is a tonal language hence altering the intonation affects meaning of sentences and words.

\section{B. Analysis of Prayer Text 2 (P. T. 2 Ref. Appendix I)}

This prayer is performed during the fowl immolation. The prayer opened with an appeal to the divinity to accept the sacrifice of the fowl presented. Sometimes among the Kasena, the congregation after immolating the victim of sacrifice throws it down to see whether it will lie supine to mean the sacrifice is accepted by the divinity or the ancestors.

Themes: The major themes of the prayer are that of belief, reverence and need. These themes were delineated using the aesthetic devices identified in the prayer below. 
Style: Use of Words

\section{Repetitions of Varying Degrees:}

\section{Anaphora;}

In the following lines (Ref. Appendix I, P. T. 2) the recurrences of the words "ko ná" meaning 'if you' in the beginning of lines one, four and six below constitute anaphora which the officiant uses artistically to create emphasis;

Konáwaa wane

Se $n$ jare $n$ to $n$ kwaga tetare ne

Ko nam ná ye n nyene a baa jwoji a pa dedecro

Ko ná wó ke dé maama de kazena bam waa na

A te ware a twe

Koná baa wane, ta we bakwei

If you will accept

Let it fall supine

If it is yours I won't collect it for a powerful person

If you accept we and the woman will see

I can't come near

If you won't be possible tell them to take it away

The officiant uses “ko ná” meaning 'If you' which begins a conditional clause because of the belief and reverence they have for the divinity who has the final decision. effect:

The anaphora "Zane" 'get up' is repeated in lines one and three as below for mystic
Zaje
Zaje
Get up
Get up again
Get up

Da-n ta jwoori n zaje

Traditional chants, runes and prayers make much use of repetition. This is also akin to religious rituals. Repetition is also used to draw the congregations' attention to witness whether the prayer will be accepted or not.

\section{Alliteration;}

"Yage se ko ke ko fera" meaning 'let it do what it wants' has alliteration. The / k/ in "ko" 'it' and ' $k e$ "'do' enhance a rythmic effect and makes meliflows to the ear. This line is also a parallel structure as “ $k \boldsymbol{k}$ " 'it' repeats in the line. 


\section{Religious Symbolism;}

The religious praxes of the Kasena dictate the content and structure of their prayer texts and the adoration with which it is performed. "Ko ná wó $\mathbf{k e}$..." 'If you accept ...' is a religious symbolism. Symbolism is something that stands for, stands or suggests a thought, conviction, action or entity.

\section{Personification;}

The officiant further uses the personification "ta we ba kwei" meaning 'tell them to take' to emphasise the options available to the divinity since it has the final option to accept or decline. Before this, the elder informs the congregation of his limited power to indicate his reverence of the divinity in “ $\boldsymbol{A}$ te ware a $\boldsymbol{t} \boldsymbol{w} \boldsymbol{\varepsilon}$ ” which means 'I can't come near'.

\section{Rhetorical Question;}

The prayer ends with a rhetorical question, “A daawokekotemo?” meaning "what will I do to it again?' which indirectly informs the congregants of the confidence of the officiant in offering the prayer.

\section{Analysis of Prayer Text 3 (P. T. 3 Ref. Appendix I)}

The officiant opens this prayer with a re-declaration of the purpose of the prayer as in prayer text 1 . He did this by giving reasons why Kukula should accept the collection of his praises for the study.

Themes: Prayer 4 explores two major themes. They are the themes of dependency on the divinity and reverence of the same.

Style: The prayer was performed using a simple and appropriate diction for the easy appreciation of the congregants.

\section{Repetitions of Varying Degrees:}

Anaphora: What is very observable in many Kukula prayers are anaphora. In the following line there is the reoccurrence of " $\mathrm{O}$ " 'he', in the beginning of the two lines below:

O we o lageKukula lei

O lage o ja o vwo o ma o ketonomo

He says he wants Kukula songs

He is going to use them for his education

This device forms a rhythmic pattern which leads to a third repetition of /o/.The /o/ sound repeated at the beginning of the two lines and also serves as an anaphora.

Assonance: The /o/ in the above creates assonance in the second line above. This assonance creates internal rhyming in the prayer making it pleasant to the ears.

There is anaphora in the lines below as "pa se" meaning 'and' is repeated at the beginning of the three lines belowto create emphasis and a rhythmic pattern.

Pa se ba ba bwoni amoWekeimbuBanebe

Pa se a nuyi chichira a ba naa 
Pa se buwom we o lage o ja Kukula seina o vwo o ke ton n naa

And they came to call I Wekeim's son Banebe.

And I came from my chichira (depicting farm)

And the boy says he wants Kukula praises for his education.

This is reflected by the use of the conjunction 'and'.

Alliteration: In line 1 above the /b/ in "ba ba bwoji”" meaning 'they came to call' creates alliteration for rhyming effect.

2. Parallelism: The above two lines are parallel in structure as well. The second line above is a perfect instance of a parallel structure.

3. Personification: Personification is used in line 10, "Kukula jwoni sana bam" which means 'Kukula collect the alchohol'. This line indicates how the officiant and his people revere the divinity. By attributing human characteristics to the divinity the officiant was implying that the divinity knows and fulfils their desires.

\section{Conclusion}

The study shows that Kukula prayers are artistic compositions, even though the performers are merely performing religious activity, they do use artistic language in their compositions. A study of these prayers text reveals that these performers have a mastery of many artistic devices native to Kasem. Hence prayertexts thus play an important role in the oral literary performance among the Kasena. The prayers of the Kasena are invariably artistic and make their audience determine whether these performances in devotion to Kukula are well performed or not.

The prayers collected and analysed in this paper show clearly that this prayers are artistic compositions, what the performer has to say is compressed as far as possible in the form of allusions and allegory rather than a full narrative or descriptive form. This paper has also confirmed that these prayers are part of Kasem oral literature. This is because they are performed and transmitted by word of mouth from one age group to the other.

The study further ties in with findings of Broderick (1977) who identified some specific aesthetic phenomena and devices in Krio narrative tradition and Azasu (2007) who proved the existence of aesthetic features in African traditional religious prayers, chants and songs of the Ewe people.

Oral literature includes ritual texts, chants, epic poems, songs, creation myths, legends, proverbs and riddles. Most simply, oral literature refers to any form of unwritten art which is passed on orally or delivered by speech. The officiant of this prayers use poetics such as rhetoric questions, metaphor, personification and repetitions of varying degrees.

The main themes contained in the prayers texts are reverence, praise and dependence on their divinity for succor. Since the prayers belong to the field of Kasem oral literature it has been proven that they are inextricably integrated and are classified as traditional poems. 


\section{References}

Agu, O. (1991).Song and War. The Mixed Messages of Biafran War Songs.Journal African language and culture, vol. 4 No. 1, The literature of war, Taylor \& Francis, Ltd. Pp. 5-19.

Awedoba, A. K. (2000). An Introduction to Kasena Society and Culture through their Proverbs.Lanham: MD: University Press of America.

Broderick, S. M. (1977). The Tori: Structure, Aesthetics and Time in Krio Oral Narrative-Performance. (Ph.D. dissertation) University of Wisconsin-Madison.

Ekwunife, A.N.O. (2007).What Will be, Will beWhy Pray. Nigeria: HOSCON.

Finnegan, R. (1992). Oral Poetry.Its Nature, Significance and Social Context.Bloomington: Idiana Univ. Press.

Finnegan, R. (2005). The How of Literature. Oral Tradition, 20(2), 164-187.

Hastling J. (1993).The Audience, The Message, The Speaker, New York: McGraw-Hill.

Mbiti, J. S. (1970).Concepts of God in Africa.SPCK.

Mbiti, J. S. (1975).African Religions and Pbilosophy.2nded. Great Britain: Biddle Ltd, King's Lynn Norfolk.

Naden, T. (1998).“The Gur Languages” The Languages of Ghana.Ed. M. D. KroppDakubu. London: KPI, 12-49.

Parrinder, E. G., \&Parrinder, E. G. (1976). African Traditional Religion (p. 57). Greenwood Press.

Saussure, F. de.(1986). Course in General Linguistics. La Salle. IL: Open Court. S

Retrieved from http://paulford.com/what-is-aesthetics. on 07/29/2013.

Retrieved from http:// wmw.philosophicalsociety.com/aesthetics.btm.on 01/21/2013.

Retrieved from www.ajol.info on 03/12/2013

Retrieved from www.nou.edu.ng on $04 / 21 / 2013$

Retrieved from www.enotes.com on 2/15/2013 